\title{
High Molecular Weight Pro-Sucrase-Isomaltase in Human Fetal Intestine
}

\author{
HANNE SKOVBJERG ${ }^{(18)}$ \\ Department of Biochemistry C, Panum Institute, University of Copenhagen, Denmark and Medical- \\ Gastroenterological Department C, Herlev Hospital, Copenhagen, Denmark
}

\begin{abstract}
Summary
Sucrase-isomaltase (SI) was isolated by immunoprecipitation from the intestines of human fetuses of 16-20 wk of gestational age as one large polypeptide (pro-SI) with a molecular weight of 260,000 . Treatment with elastase converted the pro-SI into two polypeptides of apparent molecular weights as sucrase and isomaltase from normal adult intestine $\left(M_{r} 140,000\right.$ and 150,000 , respectively). The pro-SI had full enzymatic activity.
\end{abstract}

\section{Speculation}

The results indicate that human sucrase-isomaltase is synthesized as a single chain and that the pancreatic proteases play a significant role in the final processing of the molecule. The pro-SI is proposed to be present also in patients suffering from pancreatic insufficiency.

Sucrase-isomaltase (SI) is a digestive enzyme responsible for all the sucrase activity, nearly all the isomaltase activity, and for most of the maltase activity $(\sim 70 \%)$ of the small intestine. SI is localized with its major part exposed to the luminal content of the intestine and anchored to the small intestinal brush border membrane by a small hydrophobic segment [for review see (12)]. In the majority of mammals including man, SI occurs as an enzyme complex built up of two polypeptides one of which has sucrase the other isomaltase activity.

By observation on pigs whose pancreas has been totally disconnected it has been shown that SI is synthesized as a single-chain, assigned pro-SI (13). Treatment of this pro-SI with pancreatic proteases splits it into two polypeptides of apparent molecular sizes similar to those of the "final" SI (13), suggesting that the final step in the processing of SI occurs at the luminal surface of the intestine by action of the pancreatic enzymes.

In the developing human fetus zymogen granules have been detected in the pancreas as early as the 5 th month of gestation [for review see (9)]; however, the intestinal enterokinase, which is the activator for trypsinogen, does not appear until the 26-30 wk of gestation (1). This implies that the fetal pancreas does not have any proteolytic activity until this time. Fetal intestines before 26 wk of gestational age therefore provide a unique model to investigate if the biosynthesis of the human SI is likely to proceed via a large pro-SI and the possible role of pancreatic proteases in the processing of the SI.

\section{MATERIALS AND METHODS}

Anti-human-SI-IgG was obtained against normal, adult SI as previously described (14).

Two human fetuses of $16-20 \mathrm{wk}$ of gestational age were obtained after abortus provocatus. Their full length intestines were immediately cut out and frozen at minus $80^{\circ} \mathrm{C}$ until use. As control material small jejunum pieces of normal adult intestine were used (15).
Solubilization of the brush border proteins. The proximal part of each fetal intestine (approximately $0.3 \mathrm{~g}$ ) was homogenized in crushed ice in 4 volumes of a $50 \mathrm{mM}$ potassium phosphate buffer, $\mathrm{pH} 6.0$, containing $1 \%$ Triton X-100 and aprotinin $28 \mu \mathrm{g} \times \mathrm{ml}^{-1}$. The homogenate was incubated at $4^{\circ} \mathrm{C}$ for $1 \mathrm{~h}$ and subsequently centrifuged $50,000 \times g$ for $1 \mathrm{~h}$ at $4^{\circ} \mathrm{C}$. The supernatant was collected. This solubilization method released more than $90 \%$ of the total sucrase activity. Mucosal scrapings of the adult intestinal pieces were prepared in the same way.

Immunoprecipitation. $150-200 \mu \mathrm{l}$ of the supernatants containing approximately $300 \mathrm{mU}$ sucrase and $4 \mathrm{mg}$ mucosal protein was run in line immunoelectrophoresis (10) against specific anti-humanSI-lgG $(300 \mu \mathrm{g} / \mathrm{ml}$ gel) as described in (14). The fetal SI crossreacted immunologically with adult $S I$ as it precipitated with the IgG made by immunizing rabbits with purified adult SI. After washing and pressing of the immunoelectrophoretic plate the immunoprecipitates (visible without staining) were excised. Rocket immunoelectrophoresis (16) of the supernatants against the specific anti-human-SI-IgG was performed as in (14).

Polyacrylamide gel electrophoresis. Gel electrophoresis in $10 \%$ polyacrylamide gels in the presence of sodium dodecyl sulphate was performed by the method of Laemmli (11). Before electrophoresis the excised precipitates were boiled for $5 \mathrm{~min}$ in the presence of $1 \%$ sodium dodecyl sulphate and $2.5 \% 2$-mercaptoethanol. In some experiments the excised precipitates were soaked in elastase solution (final concentration $0.1 \mathrm{mg} \times \mathrm{ml}^{-1}$ ) at $37^{\circ} \mathrm{C}$ for $15 \mathrm{~min}$. The reaction was stopped by addition of phenylmethansulfonylfluorid (Merck, Darmstadt, F.R.G.) (final concentration $10 \mathrm{mM}$ ) and denatured as described above.

Assays. The sucrase and isomaltase activities were analysed according to Dahlqvist (5) using sucrose and isomaltose as substrates. The enzyme activity is expressed in units (U), i.e., $\mu$ moles of substrate hydrolyzed $\times \min ^{-1}$. The protein concentration was measured according to Bradford (4) (Bio-Rad Laboratories, $\mathrm{Mu}$ nich, F.R.G.) using bovine serum albumine as a standard.

\section{RESULTS AND DISCUSSION}

The results of the polyacrylamide gel electrophoresis are shown in Figure 1. The SI from adult intestine is shown to be built up of two polypeptides with apparent molecular weights of 140,000 and 150,000 . This result is in accordance with earlier studies on this enzyme from human, rabbit, rat, and pig intestine. It is known that the bigger polypeptide is isomaltase and the smaller, sucrase [for review see (12)]. In contrast, the fetal SI is shown to be present as one polypeptide with a molecular weight of 260,000 . By treatment with elastase this high-molecular weight SI is partially split into two bands of almost the same molecular weight as the adult SI (Fig. 1).

The ratio between sucrase and isomaltase activity for the fetal enzyme was similar to that of the adult enzyme (isomaltase activity/sucrase activity $\sim 0.7$ ). When equal amounts of sucrase activity in the fetal and the adult supernatants were analysed in rocket immunoelectrophoresis against the specific anti-SI-IgG 


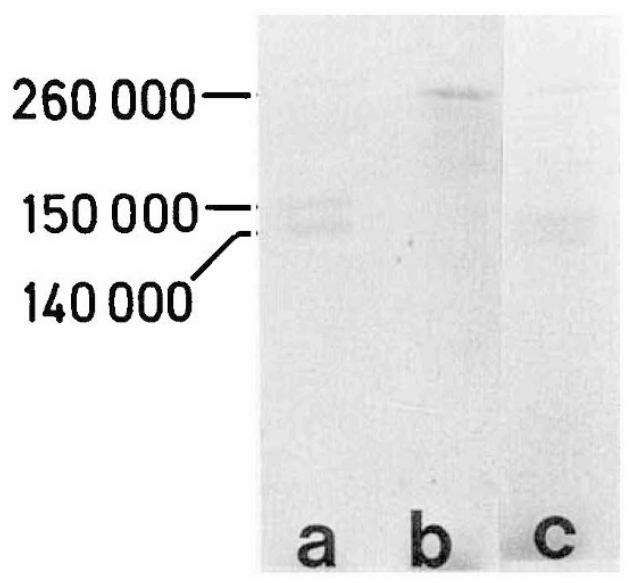

Fig. 1. Polyacrylamide gel electrophoresis in sodium dodecylsulphate of fully denatured sucrase-isomaltase (SI) from: $(A)$, adult intestine; $(B)$, fetal intestine; and $(C)$, fetal intestine after treatment with elastase. The SI was purified by immunoprecipitation before polyacrylamide gel electrophoresis as described in "Materials and Methods." Approximately 300 mU sucrase was applied (if the specific activity of the SI is similar to that of the pig enzyme (13) it corresponds to $20 \mu \mathrm{g}$ of protein). Normal SI ( $\mathrm{M}_{r}$ $140,000$ and 150,000$)$ and pro-SI $\left(\mathrm{M}_{\mathrm{r}} 260,000\right)$ from pig intestine (13) were used as molecular weight indicators.

(data not shown) the obtained precipitates were of the same size indicating the same specific activity for the two enzymes.

High molecular weight pro-SI has been demonstrated in intracellular membranes from rat (7) and pig (6) enterocytes. Evidence for the influence of pancreatic enzymes on the structure of the SI after its insertion into the microvillar membrane was provided by experiments on pigs with experimentally disconnected pancreatic ducts (13) and on subcutaneous transplants of intestinal biopsies from rats (8). In these studies SI was found in the microvillar membrane as a single large $\left(\mathrm{M}_{\mathrm{r}} 260,000\right)$ polypeptide chain which upon elastase treatment was converted into two bands nearly identical to those of "final" SI.

The present results demonstrate the existence of a fully active one-polypeptide-SI in human fetal intestine. It is the first indication that the biosynthesis and membrane insertion of the human SI is likely to proceed via a one polypeptide chain, "pro-enzyme."

Elastase is shown to split the human fetal "pro-SI" into its mature forms, which strongly suggests that the pancreas plays a major role in modifying the structure of this enzyme. Due to the small amount of material we have not examined if the fetal pro-SI is split by other pancreatic enzymes too. This is, however, likely to be the case as the pig pro-SI is not only split into its two constituent polypeptides by treatment with elastase, but also by treatment with trypsin and chymotrypsin (13).

Previous studies on patients with pancreatic insufficiency indicate that they have an increased sucrase activity (2). From the present work it might be expected that their sucrase activity is due to the pro-SI. The pro-SI and the "final" SI from normal intestine have evidently the same specific activity and the increased activity in pancreatic insufficient patients is therefore proposed to be due to the presence of an increased number of molecules and not to an enzyme with increased activity.

Recent studies by Auricchio et al. (3) indicate that the electrophoretic mobility of the human fetal microvillar enzymes differ from that of the adult enzymes, and they have some indications that this is due to differences in glycosylation. The intestines used in their study were from fetuses of the same age as used in the present work and therefore without exocrine pancreatic enzymes. In this connection another interesting question is if the pro-SI expected to be found in pancreatic insufficient patients, also have an electrophoretic mobility differing from the normal enzyme.

\section{REFERENCES AND NOTES}

1. Antonowics, I. and Lebenthal, E.: Developmental pattern of small intestinal enterokinase and disaccharidase activities in the human fetus. Gastroenterology, 72: 1299 (1977).

2. Arvanitakis, C. and Olsen, W. A.: Intestinal mucosal disaccharidases in chronic pancreatitis. Am. J. Dig. Dis.. 19: 417 (1974).

3. Auricchio, S., Caporale, C., and Santamaria. F.: Human fetal intestinal brush border sucrase, oligoaminopeptidase and dipeptidylaminopeptidase. Pediatr. Res., 15: 1193 (1981).

4. Bradford, M. M.: A rapid and sensitive method for the quantitation of microgram quantities of protein utilizing the principle of protein-dye binding. Anal. Biochem., 72: 248 (1976).

5. Dahlquist, A.: Assay of intestinal disaccharidases. Anal. Biochem., 22: 99 (1968)

6. Danielsen, E. M., Sjöström, H., and Norén, O.: Biosynthesis of intestinal microvillar proteins. Putative precursor forms of microvillus aminopeptidase and sucrase-isomaltase isolated from $\mathrm{Ca}^{++}$precipitated enterocyte membranes. FEBS Lett.. 127: 129 (1981).

7. Hauri, H. P.. Quaroni, A., and Isselbacher, K.: Biogenesis of intestinal plasma membrane: posttranslational route and cleavage of sucrase-isomaltase. Proc. Natl. Acad. Sci. USA., 76: 5183 (1979).

8. Hauri, H. P., Quaroni, A., and Isselbacher, K.: Monoclonal antibodies to sucraseisomaltase: probes for the study of post-natal development and biogenesis of the intestinal microvillus membranes. Proc. Natl. Acad. Sci. USA., 77: 6629 (1980)

9. Kimura, R. E. and Warshaw, J. B.: Intrauterine development of gastrointestinal tract function. In: E. Lebenthal: Textbook of Gastroenterology and Nutrition in Infancy. Vol. 1 pp. 39-48 (Raven Press, New York, 1981).

10. Kröll, J.: Line Immunoelectrophoresis. In N.H. Axelsen, B. Weeke: A Manual of Quantitative Immunoelectrophoresis. Methods and Applications. pp. 61-67 (Universitetsforlaget, Oslo, 1973).

11. Laemmli, U. K.: Cleavage of structural proteins during the assembly of the head of bacteriophage $T_{4}$. Nature, 227: 680 (1970).

12. Semenza, G.: Intestinal oligo- and disaccharidases. In: J. D. Whelan: Carbohydrate metabolism and its disorders. Vol. 3, pp. 133-145 (Academic Press, New York, 1981).

13. Sjöström, H., Norén, O., Christiansen, L., Wacker, H., and Semenza, G.: A fully active two-active site, single chain sucrase-isomaltase from pig small intestine. Implications for the biosynthesis of a mammalian integral stalked membrane protein. J. Biol. Chem., 255: 11332 (1980).

14. Skovbjerg, H. and Krasilnikoff, P. A.: Immunoelectrophoretic studies on human small intestinal brush border proteins. The residual isomaltase in sucrose intolerant patients. Pediatr. Res., 15: 214 (1981).

15. Skovbjerg, H., Norén, O., and Sjöström, H.: Immunoelectrophoretic studies on human small intestinal brush border proteins. A qualitative study of the protein composition. Scand. J. Clin. Lab. Invest., 38: 723 (1978).

16. Weeke, B.: Rocket immunoelectrophoresis. In: N. H. Axelsen, B. Weeke: A manual of quantitative immunoelectrophoresis. Methods and Applications. pp 37-46 (Universitetsforlaget, Oslo, 1973).

17. Mrs. Dorit Anthonsen is thanked for expert technical assistance.

18. Requests for reprints should be addressed to: Hanne Skovbjerg, Department of Biochemistry C, The Panum Institute, Blegdamsvej 3, DK-2200 Copenhagen $\mathrm{N}$, Denmark

19. This research was supported by grants no. 12-1761 of the Danish Medical Research Council, no. B 1160 of the P. Carl Petersens Fond and the Novo Foundation.

20. Received for publication December 29, 1981.

21. Accepted for publication May 18, 1982. 